\title{
The interactional achievement of speaker meaning: Towards a formal account of conversational inference
}

\begin{abstract}
Dominant accounts of 'speaker meaning' in post-Gricean contextualist pragmatics tend to focus on single utterances, making the theoretical assumption that the object of pragmatic analysis is restricted to cases where speakers and hearers agree on utterance meanings, leaving instances of misunderstandings out of their scope. However, we know that divergences in understandings between interlocutors do often arise, and that when they do, speakers can engage in a local process of meaning negotiation. In this paper, we take insights from interactional pragmatics to offer an empirically informed view on 'speaker meaning' that incorporates both speakers' and hearers' perspectives, alongside a formalisation of how to model speaker meanings in such a way that we can account for both understandings - the canonical cases - and misunderstandings, but critically, also the process of interactionally negotiating meanings between interlocutors. We thus highlight that utterance-level theories of meaning provide only a partial representation of speaker meaning as it is understood in interaction, and show that inferences about a given utterance at any given time are formally connected to prior and future inferences of all participants. Our proposed model thus provides a more fine-grained account of how speakers converge on 'speaker meanings' in real time, showing how such meanings are often subject to a joint endeavour of complex inferential work.
\end{abstract}

\section{Keywords}

speaker meaning, interactional achievement, conversational inference, semantic contextualism, miscommunication, negotiation of meaning 
"meaning lies not with the speaker nor the addressee nor the utterance alone as many philosophical arguments have considered, but rather with the interactional past, current, and projected next moment. The meaning of an entire utterance is a complex, not well understood, algorithm of these emergent, non-linear, sense-making interactions" (Schegloff et al. 1996: 181)

\section{Introduction}

Since Grice's $(1957 ; 1975)$ seminal writings, the notion of 'speaker meaning' has become a familiar concept in formal pragmatics. It provides a level of theorisation that goes beyond the literal content of what is said by individual utterances, comprising the variety of implicit meanings that speakers communicate. However, what constitutes speaker meaning is not uniformly agreed, and can vary depending on one's theoretical commitments (Haugh \& Jaszczolt 2012; Kecskes 2010). For example, a speaker-centric view on meaning might take speaker meaning to refer to (i) the meaning (or range of meanings) a speaker intends to communicate, while a hearer-oriented view might consider speaker meaning as (ii) the meaning which the speaker is presumed to have intended to communicate, or even (iii) the speaker is taken to have communicated, regardless of whether he/she intended it.

In this paper we aim to combine these options in a way that can accommodate both speaker and hearer perspectives on the meanings of individual utterances (cf. Kecskes 2010, 2017; Sanders 1987, 2015). This aim is motivated by the facts that speakers and hearers sometimes need to negotiate meanings when divergences arise, and moreover, that the process of negotiation is a typical occurrence in everyday communication (see e.g. Bilmes 1986; Haugh 2008a; Kecskes 2008; Sanders 2015). This is partly due to the fact that speaker meaning is not simply a theoretical construct grounded in (a presumed) cognitive reality, but a deontological one with real-world consequences for speakers (Haugh 2013; Sanders 1987). The stakes may vary, but speakers clearly have a vested interest in being understood as they intend themselves to be understood (Kecskes 2013). ${ }^{1}$ We thus take 'speaker meaning' to be (iv) the meaning that is 'interactionally achieved' between participants (cf. Schegloff 1981), and our aim in this paper is to propose a model of this speaker meaning in such a way that accounts for both straightforward understandings - the canonical cases - and misunderstandings through the process of interactionally negotiating meanings between interlocutors. ${ }^{2}$

\footnotetext{
${ }^{1}$ Indeed, the negotiation of speaker meaning even extends to 'strategic misunderstandings' as Robles (2017) has recently demonstrated.

${ }^{2}$ We acknowledge that meaning negotiation is traditionally associated with troubles in understanding in L1-L2 interactions (see e.g. Long 1983; Varonis \& Gass 1985), and has been extensively discussed in applied linguistics (e.g. Pica 1994; Foster \& Ohta 2005; Chiang 2009). However, in this paper we are referring to meaning negotiation in the ethnomethodological sense (e.g. Garfinkel 1967; Heritage
} 
Taking the object of speaker meaning as that which is interactionally achieved runs counter to dominant contextualist accounts of speaker meaning in philosophical pragmatics (e.g. Recanati 2010; Sperber \& Wilson 1995) that provide analyses of individual utterances as they arise in conversation. On such views, speaker meaning is conceptualised as the output of a speaker's language processing system and as the input of the language processing system of another person. While such views on meaning have their place in pragmatic theory, our aim is to capture both speaker and hearer perspectives in a single notion of speaker meaning. As pointed out by Arundale (2008), this necessarily involves accounting for non-summative meanings, in the sense that inferences that interlocutors make about meanings are formally interdependent with the responses of others. As such, our notion of speaker meaning is informed not only by the speaker's inference about how he/she will be understood, but also the inference that is made available by a hearer's response about how he/she has understood that prior utterance, which in turn gives rise to further inferences of the speaker regarding the meaning of his/her own utterance with respect to how it has been understood. This takes us away from a view on speaker meaning that is informed solely by the utterance as it arises in context, but towards what has been termed the three-part architecture of conversational inference that underpins meaning (cf. Arundale 1999). So, against dominant contextualist solutions in the post-Gricean literature, our model highlights that utterance-level theories of meaning provide only a partial representation of speaker meaning as it is understood in interaction, and in this sense, our view is closer in spirit to theories of discourse structure, such as Question Under Discussion (e.g. Ginzburg 2012) and Segmented Discourse Representation Theory (Asher \& Lascarides 2003).

Note that while the term 'speaker meaning' can be used to incorporate a variety of meanings, ranging from strong to weak and from explicit to implicit, in this paper we do not attempt to model social inferences such as politeness effects, or weak implicatures (cf. Sperber \& Wilson 2015). Rather, the meaning that we aim to model here is the most salient propositional meaning that is ostensively made operative between interlocutors. Note that, as will become clear, we depart from the standard Gricean distinction between 'what is said' and 'what is meant', and instead take a view on speaker meaning that is more closely related to Jaszczolt's (2005; 2016) 'primary meaning' namely, the main 'intended' meaning of a speaker which is successfully recovered by a hearer - or Ariel's (2002) 'privileged interactional interpretation', the speaker's most relevant contribution to the discourse. ${ }^{3}$ However, while these semantic contextualist so-

1984), that is, the interactional processes by which participants (actively) shape or 'interactionally achieve' what speakers are accountably taken to mean in both L1-L2 (e.g. Kecskes et al. 2018) and L1-L1 interactions (e.g. Sanders 2017) through their responses to prior utterances.

${ }^{3}$ As Haugh \& Jaszczolt (2012) point out, intention can be understood and used in multiple different ways in modelling speaker meaning. In the subsequent discussion, we are referring to 'intention' in its ordinary, discursive sense as what speakers and hearers are licensed to infer as the main 'intended' 
lutions have gone some way towards offering a semantics of natural language utterances that converges with cognitive reality, what our model adds to these extant proposals of propositional meaning is a more fine-grained account of how speakers converge on the most salient proposition in real time that allows for divergences in understanding between interlocutors.

To exemplify the model, we focus on the phenomenon of hinting, specifically, requestive hints. Requestive hinting encompasses a particular pragmatic move in which a speaker communicates an 'off-record indirect request' (Brown \& Levinson 1987) such that the hearer is expected to figure out the speaker's intention, and so squarely fall under Jary's (2013) category of 'behavioural implicatures'. ${ }^{4}$ Typical analyses of hinting tend to focus on a single utterance that contains the hint (e.g. 'this soup's a bit bland', 'it's a bit cold in here') where the intended meaning is relatively determinate and the implicature is readily available. However, requestive hints are not always so straightforwardly recoverable, and can vary in their 'propositional opacity' (Blum-Kulka \& Olshtain 1984; Weizman 1985). Exactly because requestive hints are formulated in such a way that the content of the request is not overtly attended to, the speaker's communicative intention is presented as deliberately ambiguous and the speaker retains plausible deniability that he/she actually requested anything. Due to this ambiguity or even absence of an intention to request, a single-utterance analysis is likely to run into trouble when determining the 'meaning' of the hinting utterance (Ogiermann 2015). Examining instances of 'hinting' thus provide a fruitful testing ground for teasing out the propositions at play in such interactions.

In this paper, we first provide an overview of the literature on requestive hints, exemplifying the restrictions of a single-utterance account of speaker meaning with respect to how they are understood. In Section 3, we move to propose a formal model of the process of negotiating propositional meanings as non-summative interactional achievements, before showing, in Section 4, how the model can be applied to interactional data where offers are (more, or less, straightforwardly) prompted by what are taken to be hints. Specifically, we apply the model to a relatively simple case of negotiating meanings through the three-part architecture, to a more complex example that

meaning of a speaker. In that sense, we are sympathetic to the Relevance Theoretic position that propositional meaning is ultimately determined by the hearer's uptake (cf. Sperber \& Wilson 1995). Claims about the actual intentions of speakers or inferences about those intentions necessarily require different methodological warrants, but these go beyond the scope of the theoretical claims in this paper. We would simply note here that to locate speaker meaning in the inferences of the hearer, alongside those of the speaker, is to commit to a public notion of speaker meaning (Sanders 2013, 2015) involving a set of available inferences to which the speaker is publicly committed through what he/she says (and doesn't say) at that point in time.

${ }^{4}$ Notably, hints are regarded by Searle (1979: ix) as falling outside of the formal purview of speech act theory, but do fall within Grice's (1975) theory of conversational implicature, although they were only addressed in passing (see Grice 1987: 368). 
requires more than three turns to settle on the operative meaning, and a case in which meanings can be left more or less indeterminate between interlocutors. We conclude in Section 5, acknowledging that the three-part process of conversational inference can, of course, be short-circuited, and that two turns is very often sufficient for speakers and hearers to presume mutual understanding of attested speaker meaning. We thus provide some reconciliation between our proposal and extant accounts of 'speaker meaning' by situating single-utterance analyses of meaning within this three-part architecture.

\section{The propositional meaning of hints}

Following Brown \& Levinson (1987), an 'off-record' speech act is one that uses indirect language, that is, where the speaker means something through saying something else (Bach 2006; Davis 1998), thereby decreasing the potential for the speaker to be seen as imposing on the hearer. On a standard Gricean view of the division of labour between semantics and pragmatics, the explicitly uttered sentence is taken as the input to semantic - propositional - content, while the implicitly communicated off-record content pertains to the realm of pragmatics as a speaker-intended implicature (Grice 1975). On this view, speaker meaning is a purely pragmatic concern that lies outside the scope of semantic theory. However, against this Gricean, 'minimalist' conception of semantics is the post-Gricean view of semantic 'contextualism', which aims at delivering a view on 'what is said' that aligns with what the interlocutors themselves agree has been 'said', thus extending the degree to which pragmatic inferencing is allowed to intrude on semantic, propositional content.

Phenomena such as reference assignment, conceptual transfer, and so forth, has provided motivation for appealing to speakers' intentions to enrich the logical form of uttered sentences, in essence moving the study of propositional meaning away from formbased accounts and towards the study of a more intuition-motivated 'truth-conditional pragmatics' (e.g. Recanati 2010). On such a view, the propositional content will often be an enriched or modulated logical form, so that the sentence simply provides the input on which pragmatic processing can operate. However, as extensively noted by Jaszczolt (e.g. 2005; 2016), sometimes the strongest and most reliable way to communicate thoughts is by using indirect language. On this view, the primary meaning that is intended by a speaker is the one that is of most use to interlocutors, even if it drastically departs from the logical form of the utterance. So, despite the fact that off-record speech acts typically require hearers to make recourse to pragmatic inferencing to figure out the speaker's intended meaning, as long as the hearer can successfully recover that meaning, the implicitly communicated, indirect meaning can take on the status of the most salient propositional meaning that is available to both speaker and hearer.

The following exchange exemplifies that the speaker's main message may pertain 
to an implicitly communicated message, and that the explicit content need never be attended to, or at least can remain backgrounded.

(1) (Chad is standing in the hallway, holding his 15-month old son's hand.)

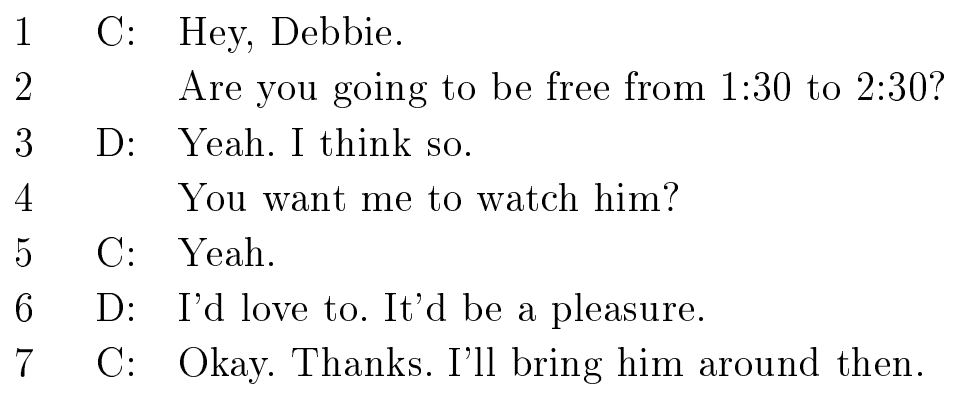

(Jacobs \& Jackson 1983: 299)

In line 2, Chad asks Debbie whether she is going to be free at a specific time later that afternoon. The standard Gricean analysis of the speaker meaning of this utterance would be that the literal, semantic content pertains to a question - which is answered by Debbie in line 3 - but that the intended implicated (pragmatic) meaning can be calculated by considering the relevance of the question to the interaction. In this sense, Chad's question can be viewed as an off-record request for Debbie to watch his son, without directly having to ask. An analysis of a more contextualist flavour would go a step further to argue that in order to view Chad's question as an off-record request with a specific goal in mind, the question itself requires enriching so as to address the question 'free for what?' (cf. Bach 1994). It may well be the case that Debbie is willing to make herself free to watch Chad's son, but may respond differently if the supposed motivation for the question is for some other purpose, for instance, proposing that they have a meeting about a joint research paper at that time. ${ }^{5}$ That is, it is through considering the reason for Chad's question, and hence modulating the inherently vague word 'free', that Debbie can devise her response. On this view, a successful interaction is dependent on Debbie reconstructing an enriched logical form, and it is that enriched meaning that would take on the status of semantic, propositional content.

There are arguments either way for whether semantics should be more concerned with the study of explicitly or implicitly communicated thoughts. We opt out of this debate by instead proposing a third option which we find the most intuitively plausible, but also the most empirically sound. Rather than hypothesising about speakers' private, cognitive inferences, we aim to represent speakers' 'primary meanings' that are made available through their on-record inferences. That is, rather than taking a strict semantic

\footnotetext{
${ }^{5}$ Thank you to an anonymous reviewer for pointing this out.
} 
view and representing the 'literal' content of the words uttered, or a pragmatic view that hypothesises about speaker's intended meanings, we aim to represent the primary meanings that the interlocutors themselves interactionally achieve in the process of communication. A strong motivation for such a view is that, for example in (1), it is difficult to state with complete certainty the extent to which Chad had an a priori intention to ask for assistance in line 2, and hence to attribute to Chad such an intention is potentially cognitively inaccurate. Rather, we are concerned with the meanings that speakers jointly converge on: the inquiry by Chad in line 2 prompts the offer of assistance from Debbie in line 4, which is readily accepted by Chad in line 5 (Haugh 2017b: 198). Note that in straightforwardly accepting Debbie's offer, Chad does license the inference that he may well have had such an intention at the time of his initial utterance. However, it also has to be noted that this intention remains off-record up until that point. In short, it is not clear that Chad's utterance in line 2 can be taken as meaning that he wants Debbie to look after his son in his asking whether Debbie is free at that time, although it is clearly inferable.

The potential equivocality of speaker intentions underlying questions that subsequently prompt offers can be seen more clearly in the following example.

(2) (Sirl and Michael, who is staying at Sirl's place, have both stopped outside the bathroom at the same time.)

1 S: What time are you leaving this morning?

2 M: Oh, in about an hour I suppose.

$3 \quad$ Are you in a hurry to leave?

4 S: No, no. Just asking.

$5 \quad(2.0)$

6 M: Would you like to use the bathroom first?

7 S: Yeah, sure, if you don't mind.

(Haugh 2007: 94)

In asking whether Sirl is 'in a hurry' in line 3, Michael appears to have inferred from Sirl's question in line 1 that Sirl would like to use the bathroom first. Despite the fact that Sirl denies having any such intention in line 4, he subsequently does not move and continues to stand outside the bathroom door. Michael then redoes his response to Sirl's initial question in line 6 by making an offer, which Sirl then accepts. In this example we can see Sirl actively working to avoid the inference that, in asking what time Michael is leaving in line 1, he intends to communicate that he wants Michael to let him use the bathroom first. But the point is not that Michael misunderstands Sirl's intended meaning, but that Sirl responds in such a way as to avoid being accountable for 
making a request in the first place. This is possible because it remains equivocal in such cases whether a proposition that the speaker would like the hearer to do something for him/her can be attributed to these sorts of 'preliminary' questions (i.e. that are inferable as addressing felicity conditions for a request) with any certainty.

Analyses of hints in the literature on implicature have tended to overlook the crucial second and third turns which provide insights into how hints are attended to by participants. Specifically, in cases where a hint by speaker A does prompt an offer from speaker B, the way in which A responds to the offer in the third turn indicates whether A wishes to license the inference that this was indeed what he/she intended. In fact, Haugh (2017b) suggests that the raison d'être of hinting is that the third turn gives A an 'out': A is unlikely to straightforwardly accept such an offer from B, as doing so would likely expose A's intentions too clearly in a way that is socially dispreferred; instead, A will frequently hedge their acceptance, provide accounts for accepting, or even initially reject the offer in order to retain some degree of plausible deniability with respect to having had any such a priori intention.

The way in which not straightforwardly accepting an offer resists the inference that the speaker was hinting in the first place is apparent in the following example. ${ }^{6}$

(3) (Emma has been talking about needing to go out and buy some food as she doesn't have anything for dinner)

1 E: I had a little tiny bit-

2 piece a fish so I don't know I may have to go to the

3 store but you go ahead Gladys and phone it up

$4 \quad$ I think maybe

5 G: they'll send it down

6 E: ye[ah

7 G: $\quad$ can I add anything for you?

8 E: Oh honey thanks I think I'll ah let Guy go

9 G: [Yes

10 E: [Maybe get some fish.

11 G: Okay.

(Haugh 2017b: 195)

In this case, Emma initially refuses, in line 8, the offer from Gladys (line 7) following Emma's 'thinking aloud', in lines 2-3, that she'll need to go up to the shops (notably, Gladys is aware from previous conversations that Emma doesn't like to drive). However,

\footnotetext{
${ }^{6}$ For the sake of expediency, the original transcription of this interaction has been simplified, although the use of square brackets has been retained here to indicate overlapping talk. See (Haugh 2017a: 195) for a more detailed transcription and analysis of this example.
} 
Emma subsquently accepts the offer, albeit in a hedged manner (line 10). In this way, Emma resists the inference that she intended Gladys to make such an offer as a result of her previous talk, despite it being inferable. Relying on utterance-based analyses of hints is evidently not enough if we are to tap into the processes by which the meanings of such hints are negotiated.

These kinds of examples also flesh out, at least in part, Sperber and Wilson's (2015) broader argument that there are a range of speaker meanings that a hearer can pick up on from a given utterance. That is, their observation that one utterance (or act of communication) expresses an array of propositions - which range in how determinately the content can be uniquely paraphrased into a natural language sentence and the extent to which the speaker can be held to be committed to that proposition - underpins their claim that an adequate theory of communication has to go beyond Grice's notion of speaker meaning. In the remainder of this paper, we attempt to extend this broader aim by pursuing a formal generalisation of the process of negotiation between speaker and hearer in attaining speaker meaning(s) that arise through 'saying' in conversation. Our aim is not only to show that the meanings of hints are typically negotiated between interlocutors, but also what that process involves and how it occurs.

\section{Towards a formalisation of the three-part architecture of conversational inference}

Since Grice, there has been a growing debate on what constitutes 'what is said' visà-vis 'what is implicated' via individual utterances. However, rather than assuming a one-stage process of 'speaker implicates, hearer infers' (Horn 2004) of single utterances, or even a two-stage process commonly referenced in conversation analytic studies of 'adjacency pairs' (Schegloff \& Sacks 1973), we aim to show that propositions are often subject to a three-part process in which the previous 'one-stage' process is only the first part. A second part occurs when a hearer responds to a speaker's utterance $\left(u_{1}\right)$ with an utterance of their own $\left(u_{2}\right)$, thereby making publicly available his/her inference about the speaker's previous utterance, $u_{1}$. Then, a third part occurs by the speaker further responding to the hearer's $u_{2}$ with another utterance $u_{3}$, in which the speaker confirms or disconfirms the hearer's (displayed) inference as appropriate.

The process of negotiating meanings in this incremental, sequentially-grounded way has been termed the process of 'interactional achievement' (Sacks et al. 1974; Schegloff 1981). In this section we propose a model of interactional achievement in which speaker meaning is formally defined in terms of the process of negotiating meanings between interlocutors. $^{7}$ In order to postulate a formal model of the conversational inferences

\footnotetext{
${ }^{7}$ Arundale (forthcoming) makes a distinction between two-part interactional achievement (or what he terms autonomous co-constituting) and three-part conjoint co-constituting in his conjoint co-
} 
that underpin the interactional achievement of 'speaker meaning', we draw on the beginnings of a formal model of conversational inferencing found in Arundale (2013) on 'conceptualising interaction' in which he distinguishes between 'provisional' and 'operative' inferences. Arundale's proposal draws, in turn, from Krippendorff (1970), who initially modelled this kind of interaction effect in more formal terms with respect to different types of communication data. The notion of 'speaker meaning' we are focusing on here is thus a deontological one, that is, the propositional meanings of utterances in the first turn to which speakers are held accountable through the responses of hearers in the second turn, and held reflexively accountable through responding themselves in the third turn (to the hearer's response in the second turn to their initial utterance in the first turn) (Haugh 2013: 47).

Indeed, as Sperber \& Wilson (1995) argue at length, linguistic action confers on speakers a particular form of commitment. By saying things to others we are invariably held to be meaning something - although not necessarily what we've just said even if we claim to be only talking to ourselves. The level of determinacy that those propositional meanings have and the degree to which speakers are committed to them will vary depending on the specifics of the linguistic action and the mutually manifest context in which it occurs. In short, linguistic action makes available inferences about what the speaker means, and because linguistic acts are public, the inferences they make available through their utterances are also public in the sense that speakers will be held committed to what a linguistic act in a given sequential context is normatively taken to mean (Jary 2013; Sanders 2015). Our contention is that a key mechanism by which the primary propositional meanings that arise through utterances is settled upon by speakers and hearers is through subsequent responses to prior utterances. ${ }^{8}$ In what follows, we focus on the simpler case of two-person interaction, although the model is extendable to more complex multi-party interactions. ${ }^{9}$

An early attempt to clarify the three-part architecture of conversational inference that underpins speaker meaning was outlined by Haugh (2012: 186-188, 2015: 234236) drawing, in turn, on Arundale's (2008; 2010) conjoint co-constituting model of communication. The three parts (which canonically, but not always, occur in adjacent

constituting model of communication. Given our focus is more specifically on conversational inference only, we cannot do justice to the intricacies of that distinction here, and so we are using the term interactional achievement in the broad sense initially outlined by Schegloff (1981: 73).

${ }^{8}$ Readers will note that we are not offering a formal account of propositional meaning here. This is deliberate as we intend the interactional model outlined in this section to be amenable to different theoretical accounts of propositional meaning, and so remain agnostic as to which model of 'utterance meaning' might be employed in subsequent theorisation.

${ }^{9}$ At this point, it should become immediately clear that continuing to refer to 'speakers' and 'hearers' will quickly get confusing as the process of negotiating propositional meaning involves more than one speaker; to avoid such complications we avoid referring to 'hearers' at all, instead making reference to speakers A and B respectively. 
turns) go as follows:

1. A produces an utterance $u_{1}$, making available an inference about how they expect $u_{1}$ to be understood;

2. B responds with $u_{2}$, making available an inference about how they think A expected $u_{1}$ to be understood;

3. A responds to $\mathrm{B}$ by way of $u_{3}$, making available an inference about how they think B has understood how A expected $u_{1}$ to be understood.

Through this three-part process, the inferences that A and B make available with regard to a particular utterance $u_{1}$ become formally tied to one another: both A and B's inferences about $u_{1}$ become interdependent with the inferences that are made available by the other participant in the discourse, and the derivation of meaning is not simply an independent process based on the utterance alone. In other words, when we speak, we draw inferences about what is meant by ourselves and others, but these inferences are driven in part by our interlocutors' inferences about what we mean and vice-versa.

Krippendorff (1970) formally distinguishes (i) an inference at time $t$, (ii) whose inference is being made (A or B), and (iii) what the inference is directed towards $(u)$. On this model, the inference at $t_{2}$ is dependent on the inference at $t_{1}$. While Krippendorff used this notation to describe different types of data, we use it as a base on which to develop an account that both uses the type of interactional data he advocates, and advance this formalisation to model speaker meaning. Using Krippendorff's terminology, then, we can formally distinguish inferences at time $t_{1}$ and inferences at time $t_{2}$. A key argument of this paper is to show that these are not straightforwardly the same thing.

Acknowledging these three variables (utterance $u$, time $t$, and whose inference, A or B) gives us the potential power to represent the meaning of any utterance at any point in time and as understood by any speaker. Doing so will highlight when discrepancies in presumed meanings arise between individual speakers. However, what is needed is a way of identifying the formal dependency between the inferences made by individual speakers on the meanings of specific utterances. To this end, we take our anchor to be the meaning of a given utterance $u_{1}$ which occurs at time $t_{1}$ (i.e. the time of utterance), such that all inferences in the model are with regard to this anchor.

We are now in a position to describe our model. Assuming a two-person interaction, we let $A$ be speaker A's inference with regard to $u_{1}$, and $B$ be speaker B's inference with regard to $u_{1}$. When $\mathrm{A}$ produces an utterance $u_{1}$ at $t_{1}$, A makes available an inference about the way in which $\mathrm{A}$ expects $u_{1}$ to be understood, and this inference is made publicly available by way of the content of the utterance in that sequential context. We call this $A_{\mathrm{Pb}\left(t_{1}\right)}$. It is on the basis of this publicly available inference that $\mathrm{B}$ is able 
to make a private inference at $t_{1}$ about what $\mathrm{A}$ intended to communicate, which we denote $B_{\mathrm{Pv}\left(t_{1}\right)}$. So at $t_{1}$ we have two sets of inferences: the public inference about what is meant through $u_{1}$ at $t_{1}$ that is made available by speaker $\mathrm{A}$ through uttering $u_{1}$, and the private inference that we (as analysts) presume speaker B makes on the basis of $\mathrm{A}$ uttering $u_{1}$ at $t_{1}$.

$$
A_{\mathrm{Pb}\left(t_{1}\right)} \longrightarrow B_{\mathrm{Pv}\left(t_{1}\right)}
$$

While Horn (2004) distinguishes 'implicatures' - meanings that are speaker intended - and 'inferences' that are hearer interpretations, we do not make such a distinction and use the term 'inference' throughout to highlight the idea that we are tracing the (presumed) private inferences that people make on the basis of the inferences that they make publicly available via their utterances.

In recognition of the fact that speakers $d o$ have (private) beliefs about the way in which they expect to be understood by their utterances, we add a previous layer into the model which we describe as the speaker's private inference regarding the meaning of $u_{1}$, denoted $A_{\mathrm{Pv}\left(t_{0}\right)} \cdot{ }^{10}$

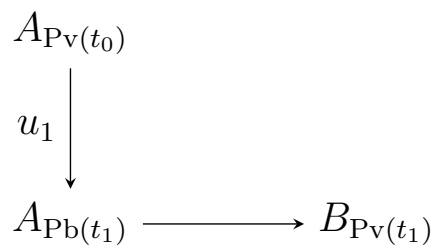

It is this private inference that can feasibly be equated with a notion of intended content. But as we cannot get into the heads of speakers this information is for representational purposes only. ${ }^{11}$ Rather, the public inference that A makes available does exactly that: makes available an inference (or set of inferences) about how A expects to be understood.

By the same token, note that neither A nor the analyst are privy to the inference $B_{\mathrm{Pv}\left(t_{1}\right)}$ that B privately makes about A's utterance $u_{1}$. The analyst can only make assumptions about what this inference is on the basis of the inference that $B$ makes available via their reply in $u_{2}$. So, given B's presumed inference at $t_{1}$, that is, $B_{\operatorname{Pv}\left(t_{1}\right)}$, B

\footnotetext{
${ }^{10}$ Note that we do not make any claims about the speaker's cognitive processing regarding this private inference: one can think of it as constituting the speaker's a priori intended meaning, or as a post-hoc inference about his/her own utterance, depending on one's view on utterance processing.

${ }^{11}$ Regardless of whether speakers are able to engage in a process of mind reading when gauging another speaker's intended meaning, it has been suggested that one's own dominant perspective is more likely to influence interpretations of what others say (Gregoromichelaki et al. 2011; Keysar 2007), further justifying an analysis that focuses on speakers' public inferences.
} 
produces an utterance $u_{2}$ at $t_{2}$ in response, which makes available an inference about how B understood A's initial utterance, $u_{1}$. The inference that B makes available is denoted $B_{\mathrm{Pb}\left(t_{2}\right)}$.

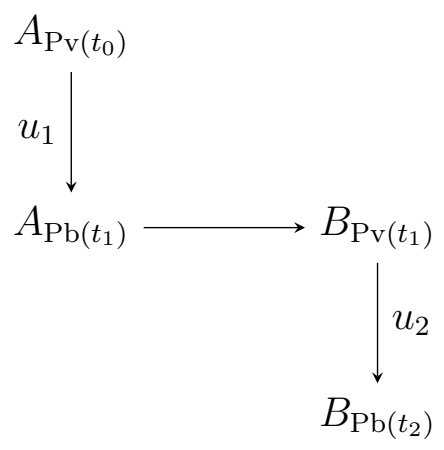

B's utterance not only makes available an inference about how they expect $u_{2}$ to be understood by A, but, crucially, it also makes available an inference about how B has understood A's utterance, $u_{1}$. And note that it is only via this inference that B makes available at $t_{2}$ that both the analyst and speaker A can make retrospective assumptions about B's presumed (private) inference at $t_{1}$ regarding $u_{1}$.

Now, once B's inference is made available about $u_{1}$, it becomes available to A whether $u_{1}$ has been understood in the way that $\mathrm{A}$ initially expected, and $\mathrm{A}$ can make a private inference about how the meaning of $u_{1}$ is being operationalized, denoted $A_{\mathrm{Pv}\left(t_{2}\right)}$.

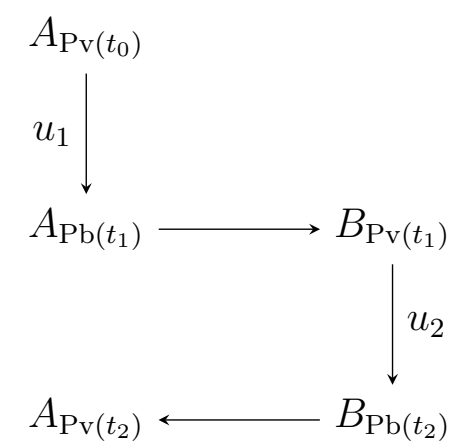

A's private inference at $t_{2}$ about how $\mathrm{B}$ has understood $u_{1}$ may or may not align with A's previous (private) inference at $t_{0}$ about how he/she expected $u_{1}$ to be understood. The third turn in the sequence thus provides an opportunity for A to do one of three things: to (i) repair the mismatch if there is one, (ii) corroborate that B has satisfactorily understood $u_{1}$ (either explicitly (e.g. 'yes', 'that's right'), or implicitly by continuing the discourse), or (iii) update their own belief on how $u_{1}$ has been understood by accepting the response by $\mathrm{B}$ and responding accordingly. 
The inference that A privately makes at $t_{2}$ about the level of convergence between $\mathrm{A}$ and $\mathrm{B}$ regarding $u_{1}$ influences the strategy that $\mathrm{A}$ chooses to employ. A's response $u_{3}$ thus makes available an inference to $\mathrm{B}$ at $t_{3}$ about the way $\mathrm{A}$ believes $\mathrm{B}$ to have understood $u_{1}, A_{\mathrm{Pb}\left(t_{3}\right)}$, which then leads $\mathrm{B}$ to make a private inference at $t_{3}$ about A's initial utterance $u_{1}$ at $t_{1}, B_{\mathrm{Pv}\left(t_{3}\right)}$.

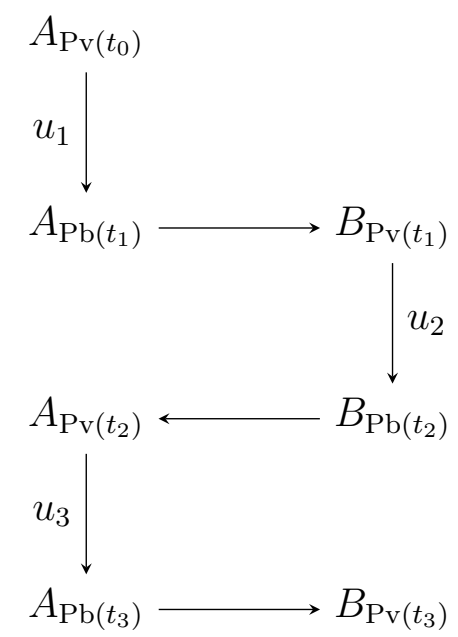

Note that it is possible to conjecture that the inference that A makes available at $t_{3}$ via $u_{3}$ not only concerns how $\mathrm{B}$ understood $u_{1}$ at $t_{2}$, i.e. the previous turn, but arguably also tells us something about A's initial expectation about how A would be understood at $t_{1}$. Indeed critically, as analysts, it is only at $t_{3}$ that we can make claims about A's presumed inference at $t_{0}$ about how $u_{1}$ would be understood by B. However, we want to avoid making claims about A's intention at $t_{0}$ on the basis of A's displayed inference at $t_{3}$. This is because, in line with A's option (iii) above, A can update their belief about the meaning of $u_{1}$ based on B's response at $t_{2}$. There are various reasons a speaker may do this: for example, because B's response was in line with the plausible interpretations A could have communicated, or because A finds it too trivial or embarrassing to correct, or a combination of the two.

In order to circumvent the idea that we are making such claims, we avoid the term 'emergent intention' (e.g. Kecskes 2010), as it is not A's intention that becomes clear over time, but rather what he/she can legitimately be taken to be meaning. A more accurate way to think about it is thus that people have intentions that can change over time; that is, the object at which inferences are taken to be directed, or intentionality more broadly, is dynamic (Haugh 2008b; Haugh \& Jaszczolt 2012). That is, whatever A's initial intention at $t_{0}$, B's response at $t_{2}$ can lead $\mathrm{A}$ to update/revise the meaning they ascribe to $u_{1}$. So rather than referring to 'emergent intentions', we can talk of 'emergent meanings', where meanings are updated as time goes on. 
Whatever meaning is made 'operative' at $t_{n}$, where $n$ is the time of some future turn in the interaction, the representation of that meaning has to be specified in relation to the process of meaning interaction from time $t_{1}$, insofar as the meanings of $u_{1}$ that emerge over the interaction are formally connected to future inferences that are made about $u_{1}$. The model thus distinguishes those inferences which are tied to a particular utterance $u$ at time $t_{1}$, and those inferences which are tied to $u$ at time $t_{n}$. If we want to represent propositional meanings, we have to do so with respect to particular times, as those meanings become cognitively available to participants. And note that in picking out the propositional meaning at a specific time, we are picking out an inference of a particular speaker (e.g. A or B) at that time, which may or may not converge with those of the other participants. In sum, inferences about $u$ at any given time $t$ are formally connected to prior $\left(t_{-m}\right)$ and future $\left(t_{n}\right)$ inferences in the sense that future inferences are dependent on past inferences, and they are all interlinked.

Finally, speakers make inferences about individual utterances $u$ at $t_{1}, t_{2}, t_{3}, \ldots, t_{n}$ until they converge on a meaning that is sufficient for the purposes of the discourse. Note that at some point, speakers will not be worrying about the meanings of prior utterances as it becomes too cognitively demanding to maintain the process as new turns occur, unless there is a catastrophic miscommunication which is later called on as the source of trouble. To this end, we leave the exact value of $n$ open as a matter for psycholinguistics to determine at what point it becomes cognitively implausible to coordinate on past meanings, although based on empirical evidence we can conjecture that $n$ typically lies between 3 and 5 as the number of turns for which it is plausible that the meaning of a 'hint' becomes 'determinate enough' that it is adequate for the purposes at hand.

\section{Putting the model to work}

With the model in place, we are now in a position to exemplify in greater detail how it can be applied to interactional data, highlighting how the meanings of critical utterances emerge over time. We begin with a relatively simple example in which a requestive hint is quickly recognised and confirmed. We then move to more complex examples, including a case where the third turn highlights problems with settling on what the speaker meant by their prior utterance, and finally an attempt to show how the model can handle cases of indeterminate meanings.

\subsection{A simple example of speaker meaning as interactional achievement}

First, let us recall the example discussed in Section 2.

(1) (Chad is standing in the hallway, holding his 15-month old son's hand.) 


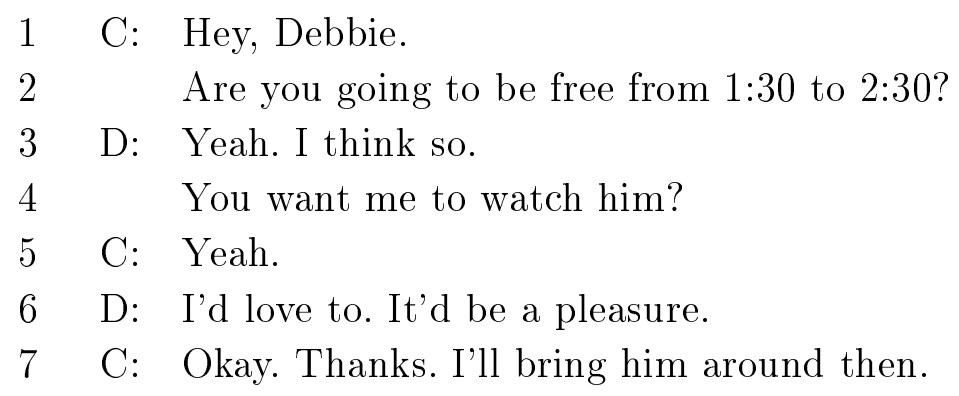

(Jacobs \& Jackson 1983: 299)

Note that we can apply the model to any utterance to track the meanings over time, but for the sake of exemplification, the crucial utterance that we take as our anchor for this example is Chad's utterance at line 2, 'Are you going to be free from 1:30 to $2: 30$ ?'. This is the utterance that we take as $u_{1}$ at time $t_{1}$. Through $u_{1}$, Chad makes available his inference about the way he expects $u_{1}$ to be understood by Debbie, giving us $C_{\mathrm{Pb}\left(t_{1}\right)}$. There are a number of options that can be inferred regarding the content of $C_{\mathrm{Pb}\left(t_{1}\right)}$, including:

$C_{\mathrm{Pb}\left(t_{1}\right) a}: \quad$ Are you going to be free from 1:30 to $2: 30$ ?

$C_{\mathrm{Pb}\left(t_{1}\right) b}$ : Are you going to be free from 1:30 to 2:30 to watch my son?

$C_{\mathrm{Pb}\left(t_{1}\right) c}: \quad$ Can you watch my son from $1: 30$ to $2: 30$ ?

Any of these is a plausible candidate that might take on the role of the primary speaker meaning of $u_{1} \cdot{ }^{12}$ But rather than speculate over Chad's intended meaning at this point, and in fact regardless of Chad's actual (private) intention at $t_{0}$ regarding how $u_{1}$ should be understood, the meaning that we are concerned with is the one that is made operative between these conversational participants.

To this end, we turn to Debbie's inference about $u_{1}$. Following Chad's uttering of $u_{1}$, Debbie is able to make her own (private) inference $D_{\operatorname{Pv}\left(t_{1}\right)}$ about Chad's putative meaning. As a reminder, we only make assumptions about Debbie's private inference about $u_{1}$ on the basis of Debbie's public utterance $u_{2}$ at $t_{2}$. We see that her initial response, 'Yeah. I think so', attends to the explicit content of Chad's question, making available a public inference about how she has interpreted $u_{1}$, landing us with a working 'speaker meaning' of $u_{1}$ as pertaining to the literal content of the question, namely:

$D_{\mathrm{Pb}\left(t_{2}\right) a}$ : Are you going to be free from 1:30 to $2: 30$ ?

\footnotetext{
${ }^{12}$ There are, of course, a range of other possible inferences, as we briefly noted in Section 2. For the sake of expediency, however, we focus on just these three.
} 
However, Debbie's immediate follow up, 'You want me to watch him?', makes available her inference that Chad's utterance $u_{1}$ may have communicated an implicit request, namely to watch his son. Thus, Debbie makes available her inference that Chad's speaker meaning may have pertained to the enriched version of the explicit question (i.e. the explicature in Relevance Theoretic terms), or even the request itself (i.e. the implicature):

$D_{\mathrm{Pb}\left(t_{2}\right) b}$ : Are you going to be free from 1:30 to 2:30 to watch my son?

$D_{\mathrm{Pb}\left(t_{2}\right) c}$ : Can you watch my son from 1:30 to 2:30?

Following Debbie making available her inference about the way that she understood $u_{1}$, namely as a request to watch Chad's son, at $t_{3}$, Chad accepts Debbie's overt invitation in $u_{3}$ with 'Yeah'. It is through this third turn that Chad makes available his inference that he does, in fact, want Debbie to watch his son, and hence that Debbie's inference regarding $u_{1}$ is compatible with Chad's overall communicative goal (cf. Elder forthcoming). So, Chad's affirmative response plays a dual role: first, of accepting Debbie's offer in $u_{2}$, but also of confirming that Debbie's inference at $t_{2}$ regarding what Chad meant by uttering $u_{1}$ was appropriate. It is only now, following Chad's $u_{3}$, that it is reasonable to postulate that both speakers have jointly converged on the speaker meaning of $u_{1}$ as:

$C_{\mathrm{Pb}\left(t_{3}\right) c}: \quad$ Can you watch my son from 1:30 to $2: 30 ?$

Notably, this latter inference arising in the third turn is formally interdependent with the inferences that were made available through the utterances in the prior two turns. In short, Chad confirming the inference that he wants Debbie to watch his son $\left(C_{\mathrm{Pb}\left(t_{3}\right)}\right)$ through $u_{3}$ depends on Debbie making available the inference that Chad wants Debbie to watch his son $\left(D_{\mathrm{Pb}\left(t_{2}\right) c}\right)$ through $u_{2}$, which depends, in turn, on Chad initially making available the inference that he wants Debbie to watch his son $\left(C_{\mathrm{Pb}\left(t_{1}\right) c}\right)$ through $u_{1}$. This can be formally represented as follows: 


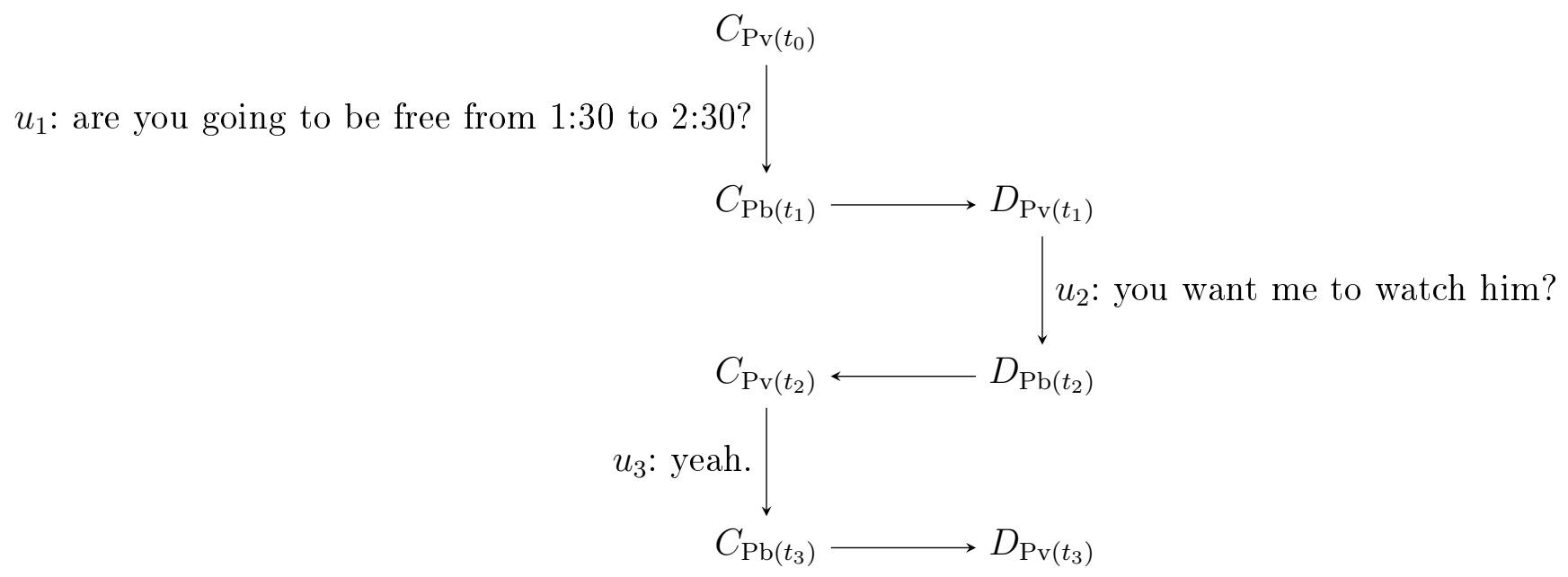

It is also important to note that even though the interlocutors converged on this meaning of $u_{1}$, we still refrain from making claims about Chad's a priori, pre-utterance intention at $t_{0}$ to make a request. Regardless of whether Chad intended to communicate a request at $u_{1}$, it is only through the uptake that is made available at $t_{2}$ and $t_{3}$ that we can say with any certainty that this implicit meaning was made operative between the two interlocutors, that is, that Chad was taken by both Debbie and himself as implying (or implicating) that he would like Debbie to watch his son. In other words, while it is plausible that $u_{1}$ communicated an implicature of a request, it is by attending to this fundamental three-part architecture of conversational inference that we can see how this aspect of 'speaker meaning' is interactionally achieved in communication, and thus that 'speaker meaning' in such cases depends on making available successive inferences that are formally interdependent with one another.

\subsection{Speaker meaning beyond three turns}

While participants often readily converge on 'speaker meaning' in the manner described above, in some instances such meanings may be worked out over a number of turns that go beyond this basic three-part architecture. While such cases are traditionally treated as instances of 'miscommunication' in need of repair by the participants and so are held to lie outside the purview of a theoretical account of 'speaker meaning', closer examination of such cases indicates that the negotiation of 'speaker meaning' may arise for a number of reasons that go beyond either straightforward 'misunderstandings' of the speaker's putative intentions, or processing errors on the part of one or both of the participants, as we briefly noted in examining cases of hinting in Section 2.

For a start, although it may sound somewhat oxymoronic, speakers do not necessarily always have determinate intentions in mind when they speak, at least, regarding the precise propositional content that they are communicating. They may speak in ways 
that leave room for the other speaker to determine what they are taken to mean (Elder forthcoming; Jaszczolt et al. 2016). Speakers may also be opportunistic with respect to what they are taken to be meaning, responding to local contingencies (Haugh 2007), or they may even change their minds, allowing what the other speaker understands them to have meant to stand as it turns out to suit them (Clark 1997). They may also subsequently dispute what they are taken to mean when they are understood in a way that turns out to have significant negative (real-world) consequences for them (Haugh 2008a). For our purposes, we contend that such instances have significant theoretical import as they attest to the way in which participants draw from the three-part architecture of conversational inference despite this negotiation occurring over successive turns.

In the following example, for instance, we can trace the way in which the meaning of an utterance is subject to subtle negotiation by the two participants. Mike (MH), a researcher, is visiting Mary (MP), his old music teacher.

(4) (Mary has offered Mike some biscuits and both have started eating them)

$\begin{array}{lll}1 & \text { MP: } & ((\text { while eating) }) \text { oh. } \\ 2 & \text { MH: } & \text { [mm } \\ 3 & \text { MP: } & \text { [I haven't gotta y'a bread 'n butter plate } \\ 4 & & \text { but there's one in the cupboard if you want one. } \\ 5 & \text { MH: } & \text { mm, oh should be okay. } \\ 6 & & \text { I'll jlu- } \\ 7 & \text { MP: } & \text { [yo[u alright? } \\ 8 & \text { MH: } & \text { [d'ya d'ya } \\ 9 & & \text { do you want one? } \\ 10 & \text { MP: } & \text { um yea- well it's le- less messier actually. } \\ 11 & \text { MH: } & \text { okay. } \\ 12 & \text { MP: } & \text { um, on the bottom shelf, } \\ 13 & \text { MH: } & \text { mhm. } \\ 14 & \text { MP: } & \text { just above the stove. }\end{array}$

(Haugh 2015: 192) $)^{13}$

As we noted before, we can apply the model to any utterance in a given example, but the critical utterance that we take as our anchor for analysis here is Mary's utterance in lines 3-4, 'I haven't got you a bread and butter plate but there's one in the cupboard if you want one'. This is the utterance that we take as $u_{1}$ at time $t_{1}$.

\footnotetext{
${ }^{13}$ For the sake of expediency, the original transcription has been simplified, apart from the representation of overlapping talk, indicated by square brackets, and cut-off words, indicated by dashes. See Haugh (2015: 191-197) for a more detailed transcription and analysis of this example.
} 
Through $u_{1}$, Mary makes available her inference about the way she expects $u_{1}$ to be understood by Mike, giving us $M P_{\mathrm{Pb}\left(t_{1}\right)}$. However, there are a number of options that can be inferred regarding the content of $M P_{\mathrm{Pb}\left(t_{1}\right)}$, as while Mary makes available an inference at $t_{1}$, which at first glance appears to be a conditional offer with Mike as the beneficiary, it could also be understood as a (polite) request with Mary or Mike as the beneficiary, or even a request with both Mary and Mike as beneficiaries:

$M P_{\mathrm{Pb}\left(t_{1}\right) a}$ : You can get a bread and butter plate from the cupboard if you want one $M P_{\mathrm{Pb}\left(t_{1}\right) b}$ : I want you to get a bread and butter plate from the cupboard for you $M P_{\mathrm{Pb}\left(t_{1}\right) c}$ : I want you to get a bread and butter plate from the cupboard for me $M P_{\mathrm{Pb}\left(t_{1}\right) d}$ : I want you to get a bread and butter plate for both of us

As in the previous example, any of these is a plausible candidate that might take on the role of the primary speaker meaning of $u_{1}$. But rather than speculate over Mary's intended meaning at this point, and in fact regardless of Mary's actual intention regarding how $u_{1}$ should be understood, the meaning that we are concerned with is the one that these conversational participants ultimately settle upon in the fifth turn, namely, that Mary is asking Mike to go and get bread and butter plates for them both $\left(M P_{\mathrm{Pb}\left(t_{5}\right) d}\right)$. Notably, settling on this inference as what $u_{1}$ comes to mean takes more than three turns. In order to account for why this happens we must first trace the inferences leading up to those made available through Mary's utterance in the third turn, and then what subsequently follows.

Starting with Mary's $u_{1}$ at time $t_{1}$ in lines 3-4 we can presume that Mike makes some kind of inference $\left(M H_{\mathrm{Pv}\left(t_{1}\right)}\right)$ about what Mary means on the basis of that utterance. Through his response $u_{2}$ at $t_{2}$ in lines 5-6 he makes available the inference that he is refusing her offer, which is predicated on the inference that through her prior utterance she was making an offer to him $\left(M H_{\mathrm{Pb}\left(t_{2}\right) a}\right)$. Mary then presumably makes an inference on the basis of Mike's response $\left(M P_{\mathrm{Pv}\left(t_{2}\right)}\right)$, the exact content of which is unknowable to us. However, the public inference she makes available through her subsequent response in line $7, u_{3}$ at $t_{3}$, is that she was not necessarily simply making an offer with Mike as the beneficiary $\left(M P_{\mathrm{Pb}\left(t_{3}\right) \neg a}\right)$. This inference is made available partly through the content of Mary's utterance itself, as asking 'you alright?' presupposes that Mike may be experiencing some kind of trouble, and partly because it is evidently interruptive of Mike's just prior response, $u_{2}$ at $t_{2}$, as we can see from the overlapping talk at this point, and Mike's consequent abandonment of whatever he was going to go on to say in line 6.

Our contention is that in Mary's making available the inference that Mike's response $u_{2}$ to her initial utterance $u_{1}$ was in some respects inapposite, that is, by Mary not straightforwardly confirming that what she meant by $u_{1}$ was that she was mak- 
ing an offer with Mike as the beneficiary, she launches a second round of three-part conversational inferencing within which the prior three interlinked inferences are embedded. In other words, Mary's question in line $7\left(u_{3}\right.$ at $\left.t_{3}\right)$ is Janus-faced (Arundale \& Good 2002) as it both retrospectively disconfirms Mike's inference that Mary was making a straightforward offer with Mike as the beneficiary (i.e. $M P_{\mathrm{Pb}\left(t_{3}\right) \neg a}$ ) but also prospectively prompts Mike to draw a different inference with respect to the getting of plates, and thus to what she meant by $u_{1}$. The public inference that is made available through $u_{3}$ at $t_{3}$ can thus be simultaneously represented in this model as $M P_{\mathrm{Pb}\left(t_{3}\right) \neg a}$ and $M P P_{\mathrm{Pb}\left(t_{3}\right) b \wedge c \wedge d}$, where the latter representation denotes the remaining inferences that are available to Mike.

However, if we continue to treat Mary's utterance in lines 3-4 as our anchor (i.e. $u_{1}$ ) - an analytical move that is arguably warranted given the orientation of the participants themselves to the issue of getting plates as not having been settled at this point - then we can see that Mike's subsequent response in lines 8-9 $\left(u_{4}\right.$ at $\left.t_{4}\right)$, which is initially delivered in overlap and thus is interruptive of Mary's just prior question in line 7 ( $u_{3}$ at $t_{3}$ ), makes available the inference that Mike is making an offer with Mary as the beneficiary, thereby retrospectively treating, and thus making available, the inference that Mary is implicating a request with Mary as the beneficiary $\left(M H_{\mathrm{Pb}\left(t_{4}\right) c}\right)$, as opposed to a request with Mike as the beneficiary $\left(M H_{\mathrm{Pb}\left(t_{4}\right) \neg b}\right)$.

Once again, however, Mary's response to Mike's offer, $u_{5}$ at $t_{5}$ in line 10, makes available the inference that Mike's response is still somehow inapposite (i.e. $M P_{\mathrm{Pb}\left(t_{5}\right) \neg c}$ ). While she initially responds in a way that appears as if she is going to straightforwardly accept the offer ('um yea-'), her confirming response is cut-off and redone with an account ('well it's less messier actually'). Through this account Mary makes available the inference that eating off plates would be better, and thus that she is making a request with both Mary and Mike as beneficiaries $\left(M P_{\mathrm{Pb}\left(t_{5}\right) d}\right)$. Mike indicates his understanding of Mary's overall communicative intention through both his verbal response ('okay' in line $11, u_{6}$ at $t_{6}$ ) and non-verbal actions (i.e. getting a plate for both of them while Mary instructs him on where the plates are kept in lines 12-14), thereby making available his final inference vis-à-vis $u_{1}$, and the one they both settle on, $M H_{\mathrm{Pb}\left(t_{6}\right) d}$.

To summarise, the conversational inferences that underpin the interactional achievement of this 'speaker meaning' can be represented as follows: 


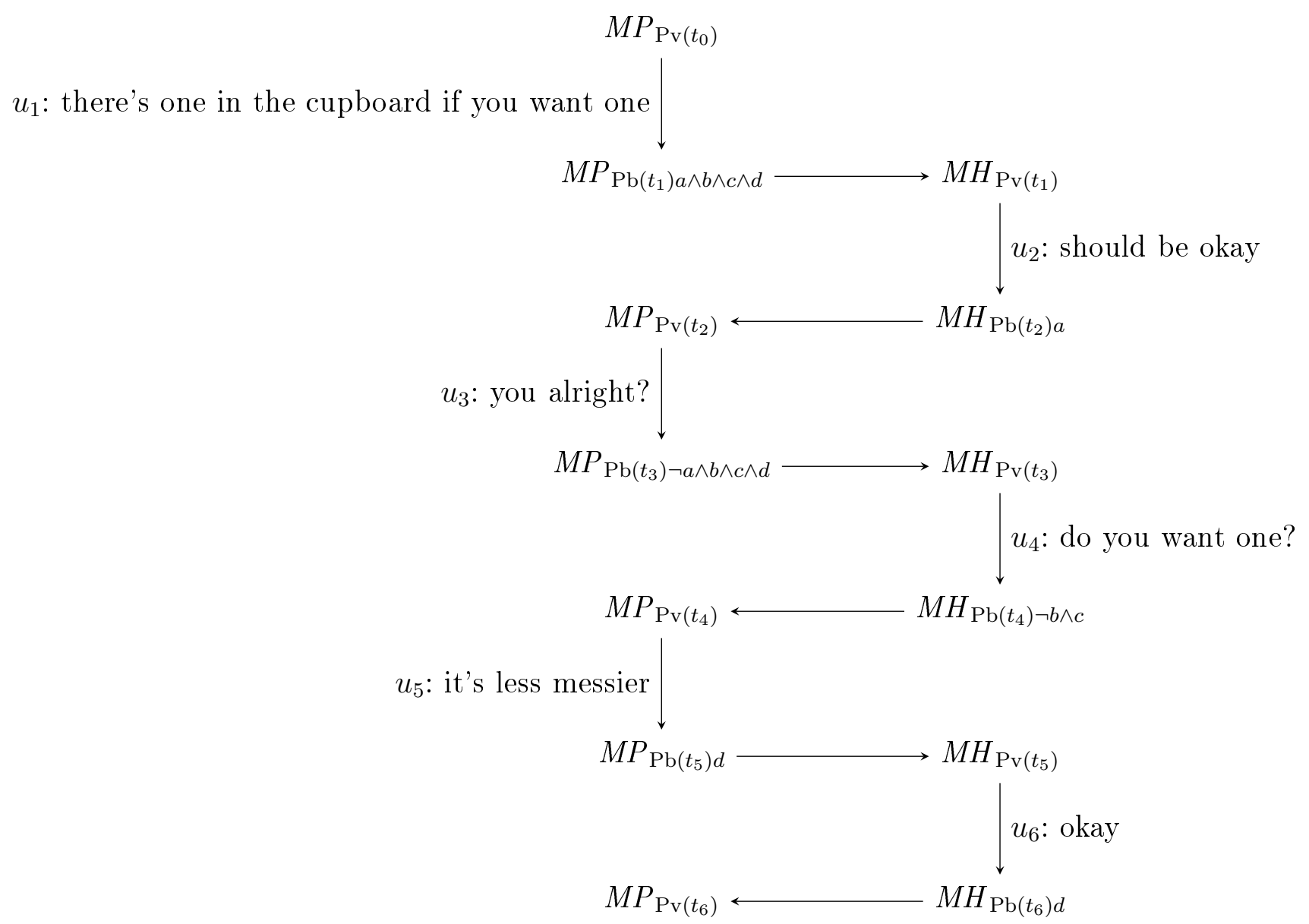

Note that the exact relationship between the public inference that Mary makes available at $t_{5}$ (i.e. $M P_{\mathrm{Pb}\left(t_{5}\right) d}$ ) which they ultimately settle upon at $t_{6}$ (i.e. $M H_{\mathrm{Pb}\left(t_{6}\right) d}$ ), and the one that Mary initially makes available $\left(M P_{\mathrm{Pb}\left(t_{1}\right) a \wedge b \wedge c \wedge d}\right)$ at $t_{1}$ is clearly open to dispute by these two conversational participants. It is possible that Mike did respond in the way that Mary consciously intended, namely as an offer of a plate, but something about the situation of discourse (e.g. that Mike was making a lot of mess when eating the biscuits) prompted Mary to respond in such a way so as to indicate something was wrong, and so she formed a post hoc intention to get Mike to eat the biscuits from a plate. However, it is also possible that Mary did intend Mike to get plates for them both all along, and that the negotiation of settling on the speaker meaning of $u_{1}$ was all in service of that initial intention.

What we can say with certainty is that we cannot say with any certainty that the final meaning that is settled on as the 'speaker meaning' is the one that Mary intended at $t_{0}$; instead, it is more empirically sound to suggest that since Mike responded in a particular way, Mary decided to continue the discourse in accordance with Mike's response. In this sense, we cannot attribute an a priori intention to Mary at $t_{0}$, as 
intentions can change over time, and hence may be ascribed to utterances in different ways at different times. Presuming a particular intention of Mary at $t_{0}$, and deciding whether Mike got it 'right' (or not), is therefore not a cognitively or empirically accurate way to analyse her utterance meaning, exactly because through making responses to her prior talk, Mike influences the inferences that Mary subsequently makes available, and vice versa. It is for this reason that Haugh (2017b) proposes that 'prompting' is a more appropriate term for this kind of phenomenon, as to treat it as 'hinting' presumes a definitive, a priori intention on the part of Mary at $t_{0} .{ }^{14}$ However, while Mary could retrospectively be taken by Mike as intentionally hinting at $t_{1}$, he (and thus we) can never be sure. What we can say for sure is that whatever her intentions might have been, the 'speaker meaning' that the two participants make operative is the one that they ultimately interactionally achieve over a series of interlinked turns of talk. So, then, in terms of propositional meaning, it doesn't really matter what Mary intended, but rather that at $t_{3}$ she makes it clear whether Mike displayed an inference that was compatible with what she plausibly could have intended (Elder forthcoming; Sanders 2015).

What should be clear from this interlinked set of representations is that these inferences are formally interdependent. That is, the public inference that Mary settles on $\left(M P_{\mathrm{Pb}\left(t_{5}\right) c}\right)$ is made available in response to the prior inference made available by Mike $\left(M H_{\mathrm{Pb}\left(t_{4}\right) b}\right)$, which is made available, in turn, in response to the prior inference made available by Mary $\left(M P_{\mathrm{Pb}\left(t_{3}\right) \neg a}\right)$, which is made available in response to the prior inference made available by Mike $\left(M H_{\mathrm{Pb}\left(t_{2}\right) a}\right)$, which is made available, in turn, in response to the inference initially made available by Mary $\left(M P_{\mathrm{Pb}\left(t_{1}\right) a \wedge b \wedge c \wedge d}\right)$ at time $t_{1}$. In other words, the latter inferences recursively embed sequentially prior ones, and so are formally interdependent with them. It is the formal interdependence of this underlying three-part architecture of conversational inference that confers the property of non-summativity on the interactional achievement of 'speaker meaning'.

\subsection{Indeterminate meanings}

The focus on adjacent turns of talk in our analysis thus far may give rise to the impression that we are privileging the local sequential context over the influence of broader contextual considerations in developing a formal model of 'speaker meaning' as interactional achievement. However, while conversational participants may very often settle on what a speaker is taken to mean by an utterance $u$ at time $t$ through adjacent turns of talk, this is not always the case, as the three-part architecture of conversational inference may well be dispersed across a number of non-adjacent turns. More importantly,

\footnotetext{
${ }^{14}$ Conversational participants may well attempt, of course, to hold a speaker accountable for having such 'intentions'.
} 
perhaps, what a speaker is taken to mean by an utterance $u$ at time $t$ may well be influenced by utterances that have occurred well before the one in question $\left(u_{-m}\right.$ at time $t_{-m}$ ) or well after it $\left(u_{n}\right.$ at time $t_{n}$ ) (Haugh 2012). Indeed, even when participants converge through the three-part architecture of conversational inference on a particular 'meaning' with respect to a particular utterance that is initially indeterminate as to what exactly is meant by that speaker, there may nevertheless remain some degree of indeterminacy for those participants with respect to what the speaker is taken to have meant.

To illustrate what we mean by this claim, consider the following example.

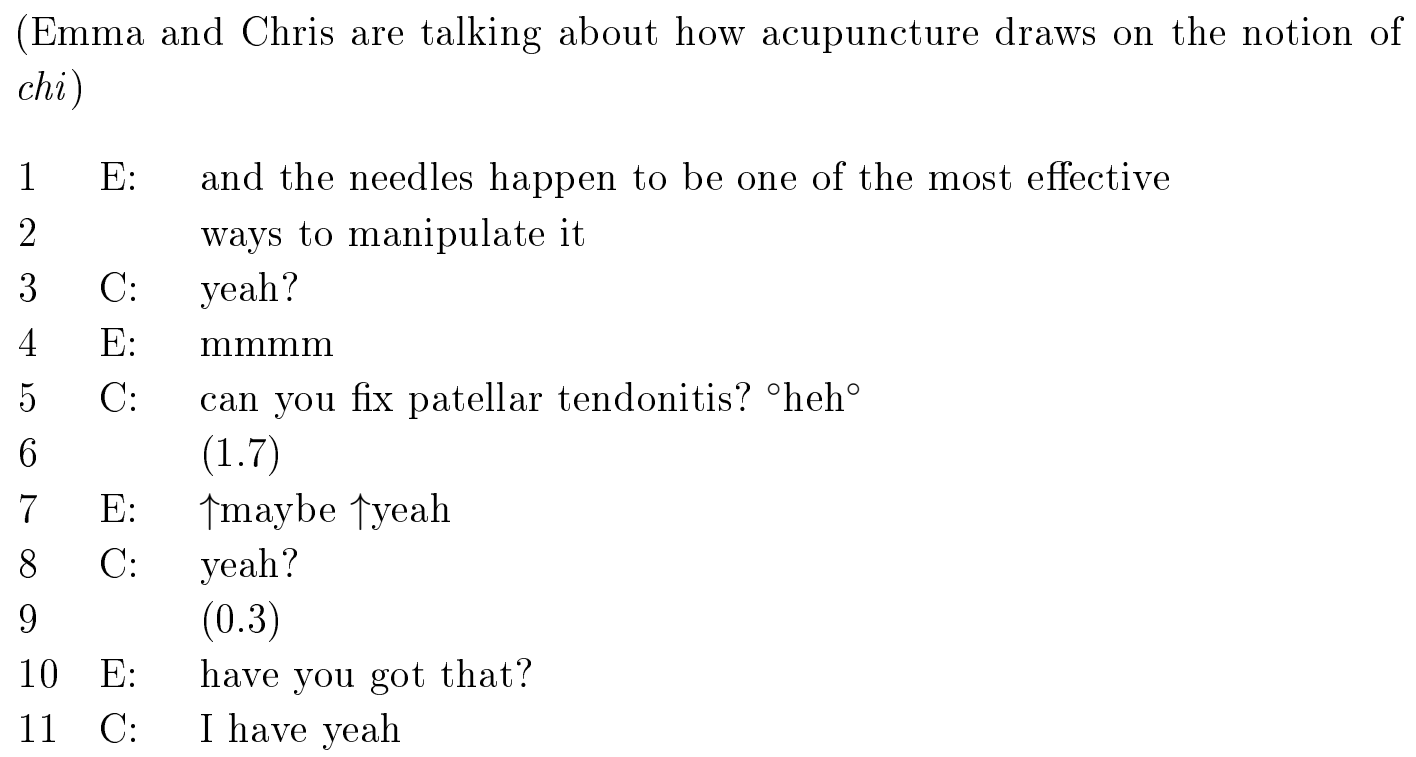

10 E: have you got that?

11 C: I have yeah

(Haugh 2008b: 63) $)^{15}$

What is meant by Chris's utterance $u_{1}$ in line 5 , 'can you fix patellar tendonitis?', appears at first glance to be genuinely indeterminate. Some of the possible inferences that he makes available include:

$C_{\mathrm{Pb}\left(t_{1}\right) a}$ : I want to know if you can fix patellar tendonitis

$C_{\mathrm{Pb}\left(t_{1}\right) b}$ : I want to know if you can fix my patellar tendonitis

$C_{\mathrm{Pb}\left(t_{1}\right) c}$ : I want you to fix my patellar tendonitis

$C_{\mathrm{Pb}\left(t_{1}\right) d}: \quad$ I doubt you can fix patellar tendonitis

\footnotetext{
${ }^{15}$ Once again, the original transcription has been simplified apart from representing softly delivered speech, indicated through degree symbols, and pauses, indicated through reporting the length of silence between utterances measured to the nearest tenth of a second in brackets. See Haugh (2015: 219-224) for a more detailed transcription and analysis of this example.
} 
While the first three possible inferences made available through Chris's utterance $u_{1}$ at time $t_{1}$ are clearly interlinked, the fourth introduces a playful, non-serious frame, and (normatively) requires a very different sort of response to that expected to the former three. This indeterminacy as to what Chris means by his question is partly a function of the way in which his question appears to come somewhat out of the blue, as previously Emma has been talking in only very general terms about how acupuncture works. Indeed, Emma only responds after a considerable pause (line 6). It is also a consequence of the way in which a (soft) pulse of laughter is appended to his question in turn-final position. Turn-final laughter can invite laughter (Jefferson 1979), which would frame Chris's question as a teasing challenge. Laughter can also orient to the action delivered through that turn as potentially disaffiliative or offensive (Clift 2012), in this case, raising the possibility that fixing this particular medical condition lies beyond what can be achieved through acupuncture. After a pause, however, Emma orients to Chris's question as potentially pre-request implicative, that is, as likely projecting a forthcoming request for treatment by Chris for that condition, and the conversation proceeds on those grounds.

Note, however, that Emma responds to Chris's question in such a way as to avoid being committed to an interpretation of it as a pre-request. By only first responding with 'maybe, yeah' in line 7, Emma makes available the inference that she has understood Chris as asking whether she is able to treat patellar tendonitis $\left(E_{\mathrm{Pb}\left(t_{2}\right) a}\right)$. She thereby withholds a pre-emptive offer that would make available the inference that she has understood Chris as implying that he would like her assistance to treat patellar tendonitis (his or someone else's for whom he is asking). Chris then responds in a way in line 8 that makes available and thus confirms the former inference (i.e. $\left.C_{\mathrm{Pb}\left(t_{3}\right) a}\right)$ but remains indeterminate with respect to the latter two inferences (i.e. $C_{\mathrm{Pb}\left(t_{1}\right) b}$ or $\left.C_{\mathrm{Pb}\left(t_{1}\right) c}\right)$. Emma's subsequent question ('have you got that?') then makes available this second inference $\left(E_{\mathrm{Pb}\left(t_{4}\right) b}\right)$, an inference that Chris subsequently confirms ('I have yeah'). In that way, then, Emma treats Chris's question as only potentially pre-request implicative, but not necessarily so. Indeed, it is only many turns later that Chris finally asks for Emma's card, thereby confirming this inference (see Haugh 2012: 181-182).

(6) (Emma and Chris have been discussing Chris's condition for over a minute)

$\begin{array}{lll}1 & \text { E: } & \text { I don't know if I could get a lasting result } \\ 2 & & \text { I don't know if I could cure it but I could } \\ 3 & & \text { [certainly] probably improve it } \\ 4 & \text { C: } & \text { [yeah ] } \\ 5 & \text { C: } & \text { yeah, your card [or ah] } \\ 6 & \text { E: } & \text { [yeah I'll] give ya a card } \\ 7 & \text { C: } & \text { yeah }\end{array}$


8 E: I'm give ya a card [now]

9 C: [will ]ing to give anything a go

(Haugh 2012: 181)

The initial three-part model can thus be extended $m$-turns preceding or, in this case, $n$-turns following the utterance that serves as the anchor for the focal 'speaker meaning' in question.

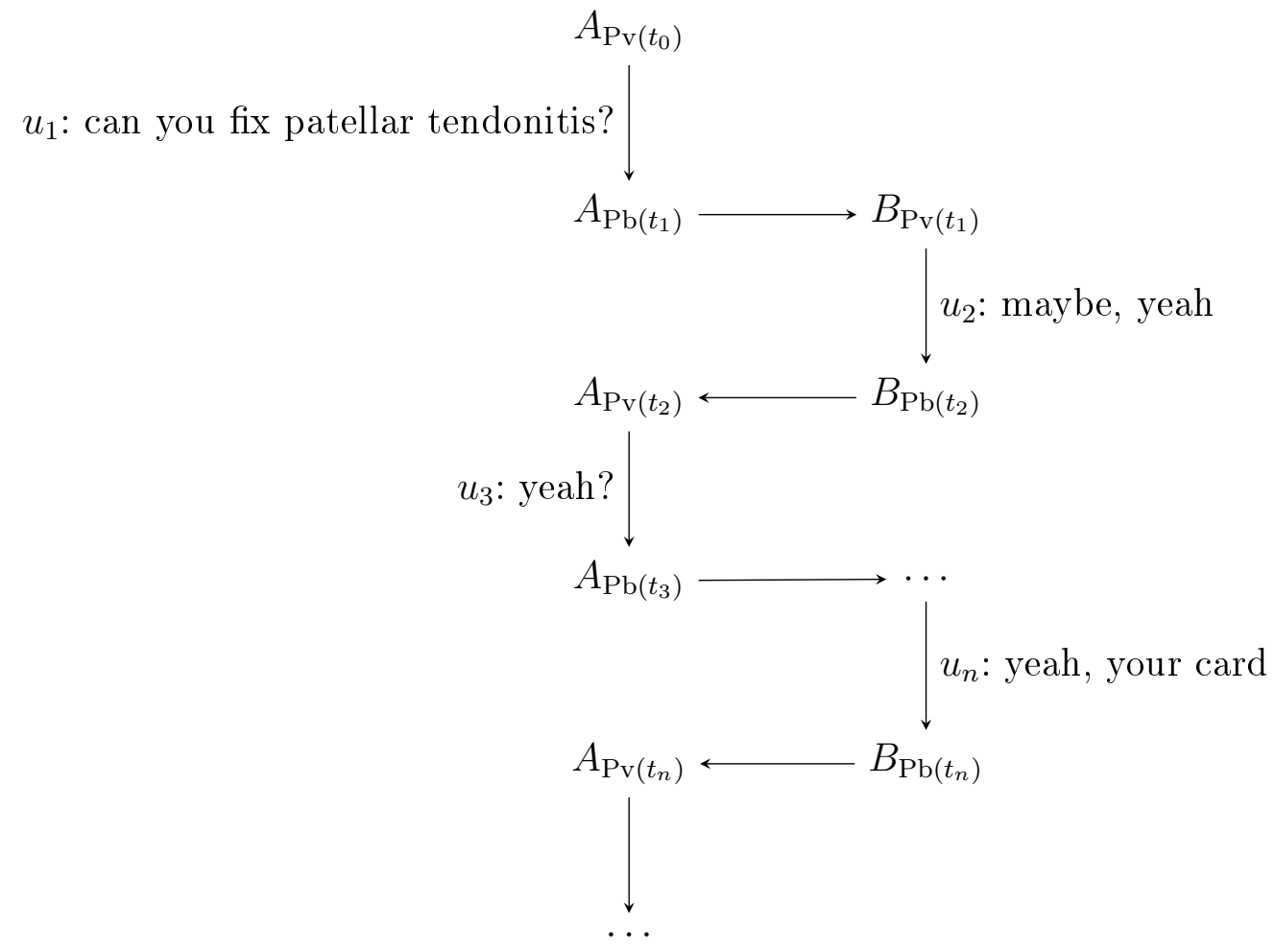

In sum, despite initial indeterminacy as to what is meant by Chris's question in line 5, Emma and Chris nevertheless move towards interactionally achieving over time an operative understanding of Chris's 'speaker meaning' here as implicating a forthcoming request for a medical consultation about that condition. Just as we saw in the case of the negotiation of what Mary initially meant in the previous example, initial indeterminacy with respect to 'speaker meaning' can be resolved through the three-part architecture of conversational inference ratcheting down as the conversation progresses.

There therefore appear to be formal grounds for the claim by interactional linguists that

"meaning lies not with the speaker nor the addressee nor the utterance alone as many philosophical arguments have considered, but rather with 
the interactional past, current, and projected next moment. The meaning of an entire utterance is a complex, not well understood, algorithm of these emergent, non-linear, sense-making interactions" (Schegloff et al. 1996: 181).

We have attempted here to formally model the conversational inferences that underpin this algorithm, and in so doing, would submit that complex, such emergent, non-linear inferential processes are nevertheless tractable - as indeed they must ultimately be given we do evidently understand each other sufficiently for us to manage the current conversational purposes at hand (at least most of the time).

It is important to note though that whatever 'speaker meaning' is ultimately interactionally achieved by the participants through that three-part architecture, other inferences that are initially made available by that utterance are not necessarily eliminated (Haugh 2017a). Whether Emma also took Chris's question as a teasing challenge remains off-record but nevertheless inferable, given the specific design and sequential placement of his question, and the scepticism about acupuncture that Chris had previously expressed in that conversation (see Haugh 2012: 182-184). While off-record inferences of the latter sort may well arise, they are by their very nature generally left off-record by conversational participants. It is for that reason that we are limiting, for the moment at least, our account of 'speaker meaning' to primary propositional meanings that are made operative between interlocutors.

\section{Conclusion}

A key question for any theory of meaning concerns the kind of meaning that is to be represented, whether that is explicit meanings pertaining to uttered sentence forms, or whether it is the most salient meanings that are (sometimes implicitly) communicated by interlocutors. Our aim has been to represent the meanings that interlocutors jointly and manifestly make use of in interaction, and hence to develop a model of speaker meaning that formalises non-summative aspects of speaker meaning that can output determinate propositional forms. While our account gives credence to the idea that an implicitly communicated implicature is sometimes the most salient meaning that is understood by interlocutors, it also shows that the main intended meaning of the speaker may not be the one that is picked up on. Rather, our account provides a fine-grained account of the formal interdependence of the conversational inferencing that interlocutors engage in when mutually operationalising meanings for current purposes. Our account therefore enables us to identify when and where mismatches in understandings between speakers occur, but also to track the resolution of understandings that may lead to meanings that weren't 'intended' at the time of utterance.

One of the key aims of this paper has thus been to extend the one- or two-turn accounts of speaker meaning that are prevalent in the extant literature to consider 
the - sometimes crucial - third turn that influences the uptake of meaning. Of course, prototypically, speakers do not have problems working out inferences of utterances in real time. It would be costly and arduous for speakers to continually confirm in the third turn that they have been understood satisfactorily, and speakers generally opt instead to simply continue the discourse. In that sense, the three-turn process can be - and is very often - short-circuited, as two turns is enough to mutually presume understanding. However, we have to understand that the one- or two-turn summative inferential process is a short-circuiting of a more complex non-summative process, by which non-summative inferences emerge through the three-part architecture that we have modelled here. But it is exactly because the formally non-summative inferences consist of interdependently linked chains of summative inferences, that the process can be straightforwardly short-circuited by conversational participants.

There are nevertheless aspects of speaker meaning that we have not addressed in this model. Speaker meaning itself is a heterogenous class (Sperber \& Wilson 2015) of which primary propositional meanings are just one type, and (as Relevance Theorists have long argued) a range of weak implicatures may also arise in communicative interaction. We suggest that the latter types of 'secondary meanings' are inevitably premised on summative conversational inferences, which, on the formal grounds we have outlined here, cannot be 'confirmed' by participants in the way that primary propositional meanings can. Moreover, side participants or over-hearers to conversation are totally reliant on a short-circuited two-stage process as they do not provide contributions by which they can make available their inferences with respect to what is being said, and so their understandings of speaker meanings are formally summative.

So while tracing the inferences that conversational participants make available through their responses to (just) prior turns of talk offers analysts a very useful tool for tracing the emergence of speaker meanings in discourse, it does not eliminate the need for other kinds of methods that allow us to tap into the private inferences that conversational participants evidently make. Our model is thus not intended to override extant accounts of meaning, and we have deliberately remained agnostic about the specifics of cognitive processing to be filled by other theories of utterance processing. Rather, our point has been that while it is possible to go from a three-part account of conversational inference (as we have proposed here) to theorising about a one- or two-stage process, the reverse is not formally possible: speaker meanings that arise through the three-part architecture of conversational inferencing cannot be reduced without remainder to those arising through one or two parts. 


\section{References}

Ariel, M. 2002. 'Privileged interactional interpretations'. Journal of Pragmatics 34 (8), 1003-1044.

Arundale, R. 1999. 'An alternative model and ideology of communication for an alternative to politeness theory'. Pragmatics 9 (1), 119-154.

Arundale, R. B. 2008. 'Against (Gricean) intentions at the heart of human interaction'. Intercultural Pragmatics 5, 231-260.

Arundale, R. B. 2010. 'Constituting face in conversation: Face, facework, and interactional achievement'. Journal of Pragmatics 42, 2078-2105.

Arundale, R. B. 2013. 'Conceptualizing 'interaction' in interpersonal pragmatics: Implications for understanding and research'. Journal of Pragmatics 58, 12-26.

Arundale, R. B. forthcoming. Communicating and Relating: Constituting Face in Everday Interacting. Oxford: Oxford University Press.

Arundale, R. B. \& D. Good. 2002. 'Boundaries and sequences in studying conversation'. In Rethinking Sequentiality: Linguistics Meets Conversational Interaction, A. Fetzer \& C. Meierkord, eds. John Benjamins Publishing Company, pp. 121-150.

Asher, N. \& A. Lascarides. 2003. Logics of Conversation. Cambridge: Cambridge University Press.

Bach, K. 1994. 'Semantic slack: What is said and more'. In Foundations of Speech Act Theory: Philosophical and Linguistic Perspectives, S. L. Tsochatzidis, ed. London, New York: Routledge, pp. 267-291.

Bach, K. 2006. 'The top ten misconceptions about implicature'. In Drawing the Boundaries of Meaning: Neo-Gricean Studies in Pragmatics and Semantics in Honour of Laurence R. Horn, B. J. Birner \& G. Ward, eds. Amsterdam: John Benjamins, pp. 21-30.

Bilmes, J. 1986. Discourse and Behaviour. New York: Plenum Press.

Blum-Kulka, S. \& E. Olshtain. 1984. 'Requests and apologies: A cross-cultural study of speech act realization patterns'. Applied Linguistics 5, 198-212.

Brown, P. \& S. C. Levinson. 1987. Politeness: Some Universals in Language Usage. Cambridge: Cambridge University Press. 
Chiang, S.-Y. 2009. 'Mutual understanding as a procedural achievement in intercultural interaction'. Intercultural Pragmatics 6 (3), 367-394.

Clark, H. H. 1997. 'Dogmas of understanding'. Discourse Processes 23 (3), 567-598.

Clift, R. 2012. 'Identifying action: Laughter in non-humorous reported speech'. Journal of Pragmatics 44 (10), 1303-1312.

Davis, W. 1998. Implicature. Intention, Convention, and Principle in the Failure of Gricean Theory. Oxford: Cambridge University Press.

Elder, C.-H. forthcoming. 'What is said in the face of miscommunication'. In Philosophical Insights into Pragmatics, P. Stalmaszczyk, ed. Peter Lang.

Foster, P. \& A. S. Ohta. 2005. 'Negotiation for meaning and peer assistance in second language classrooms'. Applied Linguistics 26, 402-430.

Garfinkel, H. 1967. Studies in Ethnomethodology. Englewood Cliffs, NJ: Prentice-Hall.

Ginzburg, J. 2012. The Interactive Stance. Oxford: Oxford University Press.

Gregoromichelaki, E., R. Kempson, M. Purver, G. J. Mills, R. Cann, W. Meyer-Viol \& P. G. Healey. 2011. 'Incrementality and intention-recognition in utterance processing'. Dialogue and Discourse 2 (1), 199-233.

Grice, P. 1957. 'Meaning'. In Studies in the Way of Words, 1989. Cambridge MA: Harvard University Press, pp. 213-223.

Grice, P. 1975. 'Logic and conversation'. In Studies in the Way of Words, 1989. Cambridge, MA: Harvard University Press, pp. 22-40.

Grice, P. 1987. 'Retrospective epilogue'. In Studies in the Way of Words, P. Grice, ed., 1989. Cambridge, MA: Harvard University Press, pp. 339-385.

Haugh, M. 2007. 'The co-constitution of politeness implicature in conversation'. Journal of Pragmatics 39 (1), 84-110.

Haugh, M. 2008a. 'Intention and diverging interpretings of implicature in the 'uncovered meat' sermon'. Intercultural Pragmatics 5 (2), 201-229.

Haugh, M. 2008b. 'The place of intention in the interactional achievement of implicature'. In Intention, Common Ground and the Egocentric Speaker-Hearer, I. Kecskes \& J. Mey, eds. Berlin: Mouton de Gruyter, pp. 45-85. 
Haugh, M. 2012. 'On understandings of intention: A response to Wedgewood'. Intercultural Pragmatics 9 (2), 161-194.

Haugh, M. 2013. 'Speaker meaning and accountability in interaction'. Journal of Pragmatics 48, 41-56.

Haugh, M. 2015. Im/politeness Implicatures. Berlin: de Gruyter Mouton.

Haugh, M. 2017a. 'Implicature and the inferential substrate'. In Implicitness: From Leixis to Discourse, P. Cap \& M. Dynel, eds. Amsterdam: John Benjamins, pp. 281304.

Haugh, M. 2017b. 'Prompting offers of assistance in interactions'. Pragmatics and Society 8 (2), 183-207.

Haugh, M. \& K. M. Jaszczolt. 2012. 'Speaker intentions and intentionality'. In The Cambridge Handbook of Pragmatics, eith Allan \& K. M. Jaszczolt, eds. Cambridge, United Kingdom: Cambridge University Press, pp. 87-112.

Heritage, J. 1984. Garfinkel and Ethnomethodology. Cambridge: Polity Press.

Horn, L. R. 2004. 'Implicature'. In The Handbook of Pragmatics, L. R. Horn \& G. Ward, eds. Oxford: Blackwell, pp. 3-28.

Jacobs, S. \& S. Jackson. 1983. 'Strategy and structure in conversational influence attempts'. Communication Monographs 50 (4), 285-304.

Jary, M. 2013. 'Two types of implicature: Material and behavioural'. Mind and Language 28 (5), 638-660.

Jaszczolt, K. M. 2005. Default Semantics: Foundations of a Compositional Theory of Acts of Communication. Oxford: Oxford University Press.

Jaszczolt, K. M. 2016. Meaning in Linguistic Interaction: Semantics, Metasemantics, Philosophy of Language. Oxford: Oxford University Press.

Jaszczolt, K. M., E. Savva \& M. Haugh. 2016. 'The individual and the social path of interpretation: The case of incomplete disjunctive questions'. In Interdisciplinary Studies in Pragmatics, Culture and Society, A. Capone \& J. L. Mey, eds. Dordrecht: Springer, pp. 251-283.

Jefferson, G. 1979. 'A technique for inviting laughter and its subsequent acceptance/declination'. In Everyday Language: Studies in Ethnomethodology, G. Psathas, ed. New York: Irvington Publishers, pp. 79-96. 
Kecskes, I. 2008. 'Dueling contexts: a dynamic model of meaning'. Journal of Pragmatics 40, 385-406.

Kecskes, I. 2010. 'The paradox of communication - socio-cognitive approach to pragmatics'. Pragmatics and Society 1, 50-73.

Kecskes, I. 2013. 'Is there anyone out there who really is interested in the speaker?' Language and Dialogue 2 (2), 283-297.

Kecskes, I. 2017. 'The interplay of recipient design and salience in shaping speaker's utterance'. In Reference and Representation in Thought and Language, M. de Ponte \& K. Korta, eds. Oxford: Oxford University Press, pp. 238-273.

Kecskes, I., R. E. Sanders \& A. Pomerantz. 2018. 'The basic interactional competence of language learners'. Journal of Pragmatics 124, 88-105.

Keysar, B. 2007. 'Communication and miscommunication: The role of egocentric processes'. Intercultural Pragmatics 4 (1), 71-84.

Krippendorff, K. 1970. 'On generating data in communication research'. The Journal of Communication 20, 241-269.

Long, M. H. 1983. 'Native speaker/non-native speaker conversation and the negotiation of comprehensible input'. Applied Linguistics 4, 126-141.

Ogiermann, E. 2015. 'Direct off-record requests? 'Hinting' in family interactions'. Journal of Pragmatics 86, 31-35.

Pica, T. 1994. 'Research on negotiation: what does it reveal about second-language learning conditions, processes, and outcomes?' Language Learning 44, 493-527.

Recanati, F. 2010. Truth Conditional Pragmatics. Oxford: Oxford University Press.

Robles, J. C. 2017. 'Misunderstanding as a resource in interaction'. Pragmatics 27 (1), $57-86$.

Sacks, H., E. A. Schegloff \& G. Jefferson. 1974. 'A simplest systematics for the organization of turn-taking for conversation'. Language 50 (4), 696-735.

Sanders, R. E. 1987. Cognitive Foundations of Calculated Speech. Albany, New York: State University of New York Press.

Sanders, R. E. 2013. 'The duality of speaker meaning: What makes self repair, insincerity, and sarcasm possible'. Journal of Pragmatics 48 (1), 112-122. 
Sanders, R. E. 2015. 'A tale of two intentions: Intending what an utterance means and intending what an utterance achieves'. Pragmatics and Society 6 (4), 475-501.

Sanders, R. E. 2017. 'Overcoming differences and achieving common ground: why speaker and hearer make the effort and how they go about it'. In Doing Pragmatics Interculturally, R. Giora \& M. Haugh, eds. Berlin: Mouton de Gruyter, pp. 31-54.

Schegloff, E. A. 1981. 'Discourse as an interactional achievement: Some uses of 'uh huh' and other things that come between sentences'. In Georgetown University Roundtable on Languages and Linguistics; Analyzing Discourse: Text and Talk, D. Tannen, ed. Georgetown University Press, pp. 71-93.

Schegloff, E. A., E. Ochs \& S. A. Thompson. 1996. 'Introduction'. In Interaction and grammar, E. Ochs, E. A. Schegloff \& S. A. Thompson, eds., vol. 13. Cambridge: Cambridge University Press, pp. 1-51.

Schegloff, E. A. \& H. Sacks. 1973. 'Opening up closings'. Semiotica 8 (4), 289-327.

Searle, J. R. 1979. Expression and Meaning. Cambridge: Cambridge University Press.

Sperber, D. \& D. Wilson. 1995. Relevance: Communication and Cognition. Oxford: Blackwell Publishing.

Sperber, D. \& D. Wilson. 2015. 'Beyond speaker's meaning'. Croatian Journal of Philosophy 15 (44), 117-149.

Varonis, E. M. \& S. Gass. 1985. 'Miscommunication in native/nonnative cconversation'. Language in Society 14, 327-343.

Weizman, E. 1985. 'Towards an analysis of opaque utterances: Hints as a request strategy'. Theoretical Linguistics 12 (s1), 153-164. 